Orbis Tertius, vol. XXVI, nº 34, e220, noviembre 2021 - abril 2022. ISSN 1851-7811

Universidad Nacional de La Plata

Facultad de Humanidades y Ciencias de la Educación

Centro de Estudios de Teoría y Crítica Literaria

\title{
La restitución de la narrativa americana en la escritura de Servando Teresa de Mier
}

\author{
The restitution of the American narrative in the writing of Servando Teresa de \\ Mier
}

\section{iD Mariana Rosetti marurosetti@gmail.com \\ Centro de Historia Intelectual-Universidad Nacional de Quilmes, Argentina \\ Instituto de Literatura Latinoamericana-Universidad de Buenos Aires, Argentina}

Recepción: 15 Abril 2021

Aprobación: 08 Agosto 2021

Publicación: 01 Noviembre 2021

Cita sugerida: Rosetti, M. (2021). La restitución de la narrativa americana en la escritura de Servando Teresa de Mier. Orbis Tertius, 26(34), e220. https://doi.org/10.24215/18517811e220

\begin{abstract}
Resumen: En este artículo analizamos la actualización de la genealogía histórico-jurídica que realizó Servando Teresa de Mier en su Historia de la Revolución como modelo estratégico y letrado de una restitución narrativa americana, a mitad de camino entre la discursividad política moderna y la discursividad tradicional del antiguo régimen.

Palabras clave: Servando Teresa de Mier, Emancipación Novohispana, Patriotismo Criollo, Narrativa Americana.

Abstract: In this article we analyze the updating of the historical-legal genealogy that Servando Teresa de Mier carried out in his History of the Revolution as a strategic and legal model of an American narrative restitution, halfway between modern political discursiveness and the traditional discursiveness of the old regime.
\end{abstract}

Keywords: Servando Teresa de Mier, New Spain's Emancipation, Creole patriotism, American Narrative.

\section{INTRODUCCIÓN}

En el año 1813 Servando Teresa de Mier publicó con el seudónimo de José Guerra su Historia de la revolución de la Nueva España antiguamente llamada Anábuac o Verdadero origen y causas de ella con la relación de sus progresos hasta el presente año en la ciudad de Londres. Esta obra es concebida por la historiografía como la primera historia nacionalista de México ya que situó e inscribió a la insurgencia encabezada por Miguel Hidalgo en Nueva España en 1810 como el corolario de una cadena de actos injustos sufridos por los americanos producto de una decadente monarquía española. ${ }^{1}$ Mier articuló el discurso histórico como plasmación de un compendio de injusticias sufridas por los americanos que debían hacerse tangibles, visibles, para los lectores ingleses de los cuales buscaba el apoyo para su intervención en América. ${ }^{2}$

Este escrito fue solicitado y financiado en una primera etapa por la esposa del virrey José de Iturrigaray (1742-1815). El acercamiento de la familia Iturrigaray a Mier (al igual que a otros letrados novohispanos) durante su estadía en Cádiz se debió a motivos de orden jurídico-moral: el ex-virrey necesitaba limpiar su nombre de toda trama de complot o rebeldía separatista americana y, a su vez, denigrar a sus opositores 
políticos que realizaron un golpe institucional al derrocarlo. En otras palabras, la esposa de Iturrigaray le solicitó a Mier el armado de una apología de la figura del virrey recientemente destituido por el golpe de Estado liderado por el comerciante Yermo y producto de la coalición de la Audiencia y el Consulado de México en el mes de septiembre de 1808. El ex-virrey había sido deportado junto con su familia a España y esperaba por los juicios de residencia y de infidencia. A pesar de haber sido indultado por el cargo de infidencia en el año de 1809, el juicio de residencia siguió en pie y tuvo su veredicto en el año de 1815, año en el que el ex-virrey falleció. ${ }^{3}$

La obra de Mier constó de catorce libros de los cuales solo los primeros siete refutaban la versión difamatoria sobre el ex-virrey Iturrigaray concentrada en el escrito del periodista Juan López de Cancelada Verdad sabida y buena fe guardada, publicada en la ciudad de Cádiz el año de $1811 .{ }^{4}$ Sin embargo, el armado y los hechos que destacó Mier a lo largo de los distintos libros, específicamente en el XIV, evidenciaron la importancia fundamental que tiene el discurso historiográfico en el período independentista hispanoamericano. Este discurso aunaba y organizaba las distintas contiendas políticas que se desarrollaban tanto en la opinión pública peninsular y americana como en las Cortes de Cádiz sobre la capacidad de representación política americana y su madurez para valerse por sí misma en el contexto de crisis de legitimidad monárquica (Cañizares-Esguerra, 1998, pp. 329-333; 2007, pp. 563-567). ${ }^{5} \mathrm{Al}$ respecto, este letrado criollo concibió la escritura de la historia de la revolución novohispana como forma de “asegurar la verdad" (Mier, 1990, p. 7) ${ }^{6}$ sobre los recientes sucesos revolucionarios acaecidos en distintas ciudades americanas. Para ello, seleccionó y analizó algunos hechos ocurridos en el período de 1810 a 1813, desestimando el valor rebelde endilgado a los escritos y actos populares o legislativos liderados por criollos. Mier construyó la verdad histórica como un arduo proceso de interpretación correcta y de puesta en diálogo de las fuentes documentales. Asumió, así, una lucha de interpretación de los panfletos, cartas, artículos periodísticos, edictos y escritos de guerra, entre otros textos, en los que se problematizó la soberanía popular. Este procedimiento retórico-discursivo, le permitió desplegar una lectura secularizada de los hechos revolucionarios o insurgentes en tanto los entendió como sucesos de reivindicación de una soberanía política propia de los vasallos americanos que en nada perjudicaba o desobedecía a la figura del rey Fernando VII. ${ }^{7}$

Para Mier, las palabras no hacían nada si no iban acompañadas de un sentido de lectura y de interpretación correctos de las mismas que les permitiera a los receptores (fueran americanos como ingleses) asir estos conceptos y utilizarlos como herramientas discursivas y actos políticos (Pasino, 2010, p. 365). En este artículo trabajamos la dedicación y persistencia de Mier sobre el discurso histórico en la búsqueda de construcción de una trama narrativa americana, armado retórico que le dio a este letrado las herramientas verbales necesarias para aprehender distintos conceptos fundamentales como fueron los de ciudadanía y soberanía y ponerlos en diálogo con la resignificación del concepto de americanos. La utilización del discurso histórico le permitió a este criollo entrelazar distintas tramas narrativas tales como la escritura apologética, el ensayo político, la manifestación o el panfleto político, la carta entre pares letrados y estipular con estas materialidades escriturarias un armado discursivo transversal en el cual primaron las figuras retóricas de la ironía y la analogía. ${ }^{8}$ Es decir, esta "historia de las circunstancias" (Mier 1990, p. 11) que parecería no tener un plan de escritura preciso, ${ }^{9}$ recurrió a la ironía para desestimar las versiones críticas tanto criollas como peninsulares sobre los hechos de emancipación americanos. La ironía le resultó útil para transformar las versiones dadas por funcionarios, militares y periodistas americanos y peninsulares sobre los hechos insurgentes americanos en cuentos o fábulas propias, según Mier, de concurrentes de cafés de poca monta o malos lectores de la Revolución Francesa. Por otro lado, o contracara de la perspectiva irónica, este letrado utilizó el procedimiento retórico de la analogía para establecer un salto histórico o descendencia cultural estratégica mediante la cual concibe al sector criollo heredero directo de las injusticias político-sociales tanto de los conquistadores españoles como de los caciques indígenas mancillados por el proceso de conquista 
española. La analogía actuó en su libro como puente de sentido necesario para estipular el linaje discursivo del discurso criollo:

\begin{abstract}
si los títulos que habéis alegado prueban algo, no prueban nada a favor de los españoles actuales, sino de los conquistadores nuestros padres; son títulos nuestros pues lo eran suyos, y vosotros queréis robárnoslos (...). Todo el género humano es originario de Asia, y nadie pretende por eso tener allá derecho, ni concedérselo a los asiáticos en las demás partes del mundo (...). Vosotros, para usurpar el título de apóstoles, habéis ocultado los vestigios evidentes de su predicación existentes en todas las Américas (...) al contrario de los Apóstoles hasta buscabais cierta analogía entre vuestros simulacros y los nuevos para sustituírselos... (Mier, 1990, pp. 584-585).
\end{abstract}

Mier estipuló una doble filiación político-social: los criollos eran hijos tanto del rey Fernando VII como de los conquistadores y los caciques indígenas castigados por funcionarios coloniales corruptos. La salida del laberinto institucional de la monarquía española solo podía darse a través de la asunción, linaje discursivo y analogía del sentir que llevaría a los criollos pasar de un padre político (el rey) a unos padres heroicos y nobles (los conquistadores y los caciques aztecas). Mier asumió este doble linaje como estrategia retórica para desestimar y condenar el legado católico impartido por los misioneros sobre los indígenas. El legado o transmisión del catolicismo fue concebido por la bula papal de Alejandro VI y por los diversos discursos jurídicos y, sobre todo, religiosos desarrollados a lo largo de los siglos XVI y XVII, como el pilar fundamental para justificar la Conquista de América. Es este legado el que desestimó Mier y lo hace a través de la creación de nuevos linajes discursivos que denunciaban las analogías perniciosas y destructivas que realizaron los primeros misioneros franciscanos en su afán de erradicar la idolatría y el canibalismo indígenas. Para lograr este objetivo, Mier configuró la propuesta independentista novohispana como acto justificado por las leyes y pactos sancionados entre la monarquía española y los nativos indianos:

...el de las Indias tenía tanto más motivo para reentrar en sus primitivos derechos en dicho caso, cuanto que aparecía jurídica y solemnemente roto por parte de los Reyes el pacto solemne celebrado con los conquistadores de Indias por los Reyes de Castilla y consignado en sus leyes de no ceder ni enajenar en todo ni en parte aquellos reinos para siempre so pena de ser nulo cuanto contra esto se ejecutasen (Mier, p. 33).

Nos interesa analizar la actualización de la genealogía histórico-jurídica que realizó Mier en su Historia de la Revolución como modelo estratégico y letrado de un entramado narrativo (White, 2003, p. 112) ${ }^{10}$ a mitad de camino entre la discursividad política moderna y la discursividad tradicional del antiguo régimen.

\title{
LA REVOLUCIÓN AMERICANA COMO RESTAURACIÓN DISCURSIVA DE DERECHOS PERDIDOS
}

En los libros VIII y XIV de su historia, Mier reflexionó sobre el concepto de revolución americana despojándolo de una perspectiva rebelde o sediciosa para dotarlo, en su lugar, de un basamento políticocultural americano relacionado con la búsqueda de autonomía. Esta lectura justificó e incorporó los hechos revolucionarios dentro de una genealogía criolla ligada a los derechos de conquista gracias a los cuales los criollos, herederos de padres conquistadores, podían hacer valer sus prerrogativas tanto sobre los territorios conquistados como sobre la administración burocrática novohispana.

La insistencia vociferante de Mier sobre un antiguo pacto entre los conquistadores y la monarquía española (avalado por la bula papal de Alejandro VI) dejó en evidencia el malestar americano dentro del engranaje burocrático-institucional. La propuesta de lectura criollista de este letrado novohispano manejó hábilmente variadas fuentes documentales (destacando ciertos fragmentos de las Leyes de Indias y de las representaciones, informes, quejas y propuestas que se publicaron en distintos periódicos europeos y se discutieron en las sesiones secretas de las Cortes de Cádiz a favor de la autonomía política americana y el reconocimiento político de todos sus habitantes). La selección precisa de ciertas leyes y documentos le permitieron a Mier estipular una relación simbiótica entre el derecho de representación política americana y la concreción de revoluciones para materializar este derecho. Su perspectiva sobre las acciones a tomar por los americanos 
pensó el accionar revolucionario como un vehículo necesario para la instalación de juntas locales que reconocieran la autoridad del monarca Fernando VII:

No, no es de admirar que ésta sea la época de la erección de Juntas en América, sino la moderación y paciencia de sus habitantes, que no las formaron desde el primer sacudimiento de la metrópoli, que descuajó los cimientos de la monarquía, siendo ellos iguales a los peninsulares en derechos para representar a Fernando (Mier, 1990, p. 224).

Esta erección de Juntas fue guiada, según Mier, por motivos legislativos. ${ }^{11}$

La paciencia de los americanos con respecto a las instituciones peninsulares en reemplazo del rey (Junta Central, Regencia, Cortes de Cádiz) y las injusticias cometidas sobre territorios americanos por parte de estas autoridades ad-hoc, precipitaron, según la perspectiva de este letrado criollo, la necesidad del accionar americano. En el libro VIII, Mier se encargó de enumerar las distintas medidas despóticas de la Regencia (parche arbitrario e insuficiente de la Junta Central) con el fin de justificar la erección de juntas locales americanas. Destacamos la causalidad inexorable que Mier estableció en este libro entre el proyecto defectuoso que llevó a cabo la Regencia en América y los sucesos de una naturaleza revolucionaria: "los ánimos están exaltados, y es de temer que las materias combustibles que se van reuniendo y amontonando en estos senos políticos produzcan de repente volcanes inextinguibles" (Mier, 1990, p. 233).

La analogía que este letrado criollo trazó entre los procesos revolucionarios asociados a inextinguibles inclemencias de la naturaleza se trató de un procedimiento narrativo propio del plan que utilizó el patriotismo criollo concebido como retórica de la restauración americana. Esta retórica implicó el uso del concepto americanos por parte del sector criollo como espejo y sinónimo del nombre indianos, ${ }^{12}$ estipulando de esta forma una transformación estratégica sobre el mote denigrante de naturales con el que se refería en las Cortes de Cádiz a las incapacidades políticas de los americanos. Esta apropiación de Mier con respecto al nombre indianos no se trató de un procedimiento novedoso en su escritura. La utilización del nombre indianos se destacó como procedimiento discursivo principal en su Sermón del 12 de diciembre de 1794 en honor a la Virgen de Guadalupe. En este sermón, que le valió el destierro de su patria Nueva España, configuró un nosotros inclusivo complejo al considerar a los criollos representantes tanto de los criollos americanos como de los naturales (indígenas) de Nueva España: "iQué gloria para los indianos! (...) i[Q]ué honra para nosotros!; ¡qué piadosa envidia para las demás naciones!, pero iqué satisfacción para la América!” (Mier, 1982, p. 736). ${ }^{13}$

El uso discursivo de Mier formó parte de una tradición narrativa propia del patriotismo criollo que abrevó en fuentes heterogéneas como fueron la Brevisima relación de la destrucciónde las Indias de Bartolomé de Las Casas (1552), los Comentarios reales del Inca Garcilaso (1609), la Monarquia indiana (1615) de fray Juan de Torquemada, el Teatro de virtudes políticas (1680) de Carlos de Sigüenza y Góngora y la Historia antigua de México (1780) de Francisco Javier Clavijero, entre otros. En estos escritos se recuperó la forma de vida previa a la conquista española y se relevaron los logros civilizatorios de los Imperios indígenas. ${ }^{14}$ Salvando las distancias entre las propuestas de cada una de las obras enumeradas, todas ellas anclaron su estudio en los aspectos culturales y económicos de los Imperios azteca e inca y reflexionaron/cuestionaron la manera apropiada mediante la cual la monarquía española debía valorar estos tesoros antiguos como modelos que contribuyeron a la configuración del buen vasallo indiano.

Por otro lado, las obras mencionadas estipularon una división entre historia antigua y moderna de las Indias considerando a la conquista española como proceso definidor de una nueva era. Si nos concentramos en el patriotismo criollo del siglo XVIII, de cara a reflexionar sobre el tratamiento particular que del mismo hará Mier, la crítica destacó las afiliaciones político-culturales que construyeron las obras de los jesuitas exiliados en el siglo XVIII con respecto a la historia de la conquista dada por los historiadores y cronistas europeos.

La labor historiográfica característica del criollismo jesuita de fines del siglo XVIII es considerada por Carlos Jáuregui como la construcción de una guardarropia histórica y cultural. Este guardarropa o archivo criollo consistió en la construcción de un discurso histórico basado en el procedimiento narrativo de la 
acumulación documental mediante el cual la ilustración criolla se apropió de los relatos, historias y tesoros culturales amerindios, así también del artefacto cultural del salvaje construido por distintas lecturas ilustradas europeas (como fueron los casos de Rousseau, Montesquieu, entre otros):

el salvaje fue el cuerpo simbólico que la Ilustración criolla le disputó a la europea y también el signo ambivalente de la asincronía americana frente a la Modernidad occidental; fue el tropo para señalar la represión española durante la independencia y al Otro indócil de los relatos nacionales (...). El salvaje fue la extrañeza familiar o amena y el locus del terror; el espejo de idílicas citas arqueológicas y el reflejo turbio de la mala conciencia de la colonialidad. Pero, sobre todo, el salvaje -buen salvaje o caníbal - funcionó como máscara o guardarropía cultural: de la insumisión política y de la insurrección, del mestizaje y del blanqueamiento, de aspiraciones de unidad y de ansiedades frente a la heterogeneidad y la fragmentación. El salvaje constituye un índice (en el sentido benjaminiano) del archivo cultural latinoamericano, de las relaciones inestables y malestares de los proyectos nacionales, de las eventuales pugnas y complicidades de los nacionalismos del siglo XIX con el (neo) colonialismo y el capitalismo global, y de los conflictos étnicos y de clase al interior de las comunidades imaginadas (Jaúregui, 2008, p. 223).

$\mathrm{Al}$ respecto, observamos en el tipo de relato a lo indiano que construye Mier un tipo de apropiación particular de la epistemología patriótica criolla ${ }^{15}$ basada en el ejercicio de lectura, clasificación y jerarquización de los documentos indígenas y del resguardo de sus archivos culturales a lo largo de los siglos coloniales a través de los letrados criollos. Mier estipula así una trama narrativa americana entendiendo la misma como un ejercicio de tejido textual tendiente a recuperar las voces, documentos propios de los archivos indígenas quemados por los conquistadores y misioneros. A su vez, este letrado criollo concibe la trama histórica como el correcto hilvanado de los documentos que informan, polemiza y traducen al pueblo los caóticos hechos de guerra civil suscitados en las distintas provincias y virreinatos americanos. Esta organización narrativa se plasmó en la obra de este letrado novohispano a través de dos ejes bien claros: por un lado, el quiebre o fractura de la Carta Magna entre los conquistadores y la monarquía española; por otro lado, el descontento antiguo de los americanos por la opresión que padecían causada por el despotismo del gobierno peninsular.

El primer eje se ligaría a la violación del derecho consagrado a los americanos criollos, la magna carta, derecho político-jurídico que estipula la igualdad de condiciones entre americanos y españoles para el ejercicio de la autonomía política:

recurro para fijar el estado de la cuestión entre españoles y americanos a principios más sólidos y absolutamente incontestables: al pacto solemne y explícito que celebraron los americanos con los Reyes de España, que más claro no lo hizo nación alguna, y está autenticado en el mismo código de sus leyes. Ésta es nuestra magna carta (Mier, 1990, pp. 475- 476). ${ }^{16}$

Con el golpe armado de Gabiel Yermo (15 de septiembre de 1808), aceptado por la Regencia y por las posteriores Cortes de Cádiz, Nueva España perdió su posibilidad de vehiculizar un cambio político dentro de los confines de la monarquía española. Esta irrupción armada, sostenida por los comerciantes peninsulares y gran parte de la Audiencia de Nueva España, generó un desvío sobre la constitucionalidad americana que pasó a dirimirse en la construcción discursiva-polémica de los debates públicos llevados a cabo en las sesiones de las Cortes de Cádiz y, sobre todo, en el diálogo entre los distintos periódicos que circulaban por Cádiz y por Londres. Este desvío de la soberanía política es considerado por Mier como la usurpación peninsular de la soberanía que "pese a las circunstancias extraordinarias, seguía perteneciendo al rey y no a las Cortes" (Goren Bitrán, 2011, p. 77). En palabras de Antonio Annino:

Para Servando había que demostrar a la opinión pública que Nueva España no sólo era una entidad natural o colonial sino, algo más: una identidad histórica con una constitución propia formada en los tiempos y que legitimaba la aspiración al autogobierno frente a las demás naciones (...9 el reconocimiento ahora era un problema internacional, pero el tema seguía siendo el mismo de 1808 (...). Constitucionalizar definitivamente el patriotismo criollo fue el objetivo de Fray Servando. La originalidad del dominico fue poner al centro de la cuestión constitucional la ilegitimidad del golpe más que la de la abdicación del rey. Con este desplazamiento de su eje central, la crisis se ubicaba y se originaba en el territorio novohispano otorgando una nueva y más fuerte legitimidad histórica al patriotismo criollo: el golpe, y no solo la abdicación, rompió lo que Fray Servando llamó la Magna Carta de Nueva España frente a la Corona, dejando el reino libre de perseguir su destino. 
El golpe era ilegal porque atentaba en contra de la legítima retroversión de la soberanía reivindicada por el cabildo de Ciudad de México (2008, p. 67).

El planteo de Mier priorizó el grave desajuste legal de Nueva España autorizado por la venia de la monarquía española que conllevó la creación de una contrainsurgencia de características monstruosas de acuerdo con los informes militares y de las Gacetas del Gobierno. En estos escritos se utilizó un lenguaje denigratorio sobre las capacidades políticas americanas y se justificó el golpe de estado realizado por Yermo. Al respecto, sostiene Mier: “¿Es de extrañar que a la vista de tantas ferocidades toda la Nueva España horrorizada haya corrido a las armas para destruir estos monstruos?” (1990, p. 393). Para Mier, este desajuste plasmado en la escritura pública de las gacetas quiso borrar la constitución que dieron los reyes a América mediante la cual se habían reconocido ciertos derechos de autonomía que no tenían otros dominios de la monarquía en Europa:

Tal es la constitución que dieron los Reyes a la América, fundada en convenios con los conquistadores y los indígenas, igual en su constitución monárquica a la de España, pero independiente de ella. Uniéronse a Castilla; pero no como Andalucía y Galicia, sino con igual principado soberano, y conservando sus leyes, fueros y pactos; y deben regirse y gobernarse, como si el Rey que los tiene juntos fuese sólo Rey de cada uno de ellos, según hablan los mejores Jurisconsultos (1990, p. 507).

Los convenios que Mier señaló entre los reyes y los conquistadores e indígenas le permitieron establecer en su escritura una lucha legal en la que los americanos criollos pudiesen ser los representantes tanto de los indígenas como de las castas americanas. A su vez, la argumentación legal basada en un pacto o constitución originaria, propia de la conquista española, contribuyó a cimentar una legalidad americana en relación directa con el rey español, cuestionando la legitimidad de la constitución de las Cortes de Cádiz:

\footnotetext{
No, nuestro pacto social no puede ser variado sin nuestro consentimiento, y nosotros ni lo hemos prestado por nuestros Diputados, que ni han sido llamados en el número correspondiente igual a su población como en España, y que han protestado las Cortes y la Constitución los pocos que han venido; ni lo hemos prestado por nosotros mismos (...). En nuestro pacto invariable no hay otro Soberano que el Rey. Si falta, la soberanía retrovierte al pueblo americano, que ni por sus leyes ni por sus declaraciones de ese mismo Congreso es súbdito de España sino su igual, y puede hacer lo que le parezca para gobernarse conforme convenga a su conservación y felicidad, que es la suprema ley imprescriptible, y el fin de toda sociedad politica, como asienta con razón la misma nueva Constitución española (1990, p. 509).
}

La propuesta de Mier no incitaba a una emancipación absoluta, sino que demandaba la revisión y reconocimientos de leyes ya promulgadas que no eran respetadas. Este letrado novohispano caracterizó el constitucionalismo americano "revolucionario en el sentido tradicional de restaurar plenamente unas imaginarias libertades antiguas golpeadas por el "despotismo regalista” (Annino, 2008, p. 30).

La lectura crítica de Annino coincide con la de Anthony Padgen en lo que respecta a la concepción de Mier de los conceptos de revolución y restauración con un agregado fundamental: para Padgen la asimilación de estos dos conceptos era una característica propia del discurso del patriotismo criollo:

[L]os rebeldes no son "revolucionarios" en el sentido que se dio a esa palabra después de 1789, puesto que no están pidiendo ningún cambio radical en la estructura de la sociedad a la que pertenecen. Lo único que piden es la restitución del statu quo; la suya es una "revolución" en el sentido primitivo y más literal de la palabra (1991, p. 189).

El cambio que tanto Camilo Torres, Juan Pablo Viscardo y Guzmán, Francisco de Miranda y Servando Teresa de Mier incitaban y reclamaban se encontraba ligado a recomponer un orden legal no reconocido en América que estipularía una equitativa distribución de empleos burocráticos para los americanos y que limitaría el despotismo de la monarquía española. La propuesta de Mier en la escritura de su historia, y en particular en su libro $\mathrm{V}$, consistió en interpretar el malestar americano con el gobierno monárquico ligado a una defectuosa valoración y un mal uso tanto por parte de los gobernantes peninsulares como por la prensa novohispana y gaditana de la trama narrativa americana. En otras palabras, sostenemos que este letrado novohispano resignificó la discursividad criolla ligada a una trama narrativa de fábulas y recuerdos planteada tanto por el Inca Garcilaso como igüenza y Góngora y Clavijero. Esta forma narrativa estipularía 
una memoria colectiva guardada en quipus, monumentos culturales y, sobre todo, en una tradición familiar que tendería a ver a los americanos como una gran familia de vecinos. Para el patriotismo criollo la tradición del relato fijado en anécdotas, recuerdos y fábulas compartidas por la comunidad poseía un carácter didácticomoral mediante el cual los individuos accedían al conocimiento de la historia de la comunidad a través de relatos transmitidos ya sea de forma oral como plasmados en objetos culturales difícilmente decodificables por el ojo imperial-económico europeo.

Por otro lado, Mier recurrió a la trama narrativa americana como vía para justificar el accionar de los colonos frente a las limitaciones y prohibiciones de la Corona española en lo tocante a las encomiendas y derechos políticos y económicos:

Éstos son los colonos de América, y que componen la principal parte de su población, tan numerosa como que, en sola Nueva España, según el cálculo de Humboldt, hay 1.200.000. Llámanse criollos, nombre, dice Garcilaso, ${ }^{17}$ que dieron los negros de Guinea a sus hijos nacidos en América, a los cuales se creían superiores. Tenían razón, porque siendo ellos libres tal vez en Guinea, sus hijos eran esclavos en América. Pero los españoles europeos ¿cómo han podido creerse lo mismo respecto de sus descendientes en América, que son hijos de los conquistadores, y caballeros y nobles? Desgraciadamente los que en América insultan a éstos son en general las heces de España, que, huyendo de la quinta, de las cárceles que merecían, y generalmente de la miseria, pasaron allá en despacho de las leyes (Mier, 1990, p. 140).

La recuperación de una memoria colectiva anclada en una trama narrativa compartida dialoga con la reivindicación de Mier sobre el accionar de los americanos, cansados de la manipulación tanto militar, económica y legal por parte de las necesidades y reconvenciones peninsulares:

Demasiada sangre han derramado ya para evidenciar que no son cobardes orangutanes, sino muy dignos de figurar al lado de los angloamericanos. (...) No es el interés de un día, sino el de muchos siglos (...). Largo tiempo hemos hablado de reconciliación y de paz. Desde que se tomaron las armas, desde que la primera gota de sangre ha corrido, pasó ya el tiempo de las discusiones. Un día ha hecho nacer una revolución, un día nos ha transportado en un siglo nuevo (Mier, 1990, p. 577).

Mier construye su historia en base a un amasijo de documentos, papeles públicos y versiones de la opinión pública, teniendo en cuenta la trama narrativa americana que implicó pensar la escritura de los hechos como un legado para los lectores americanos y europeos (en especial, ingleses)el caos de su argumentación, así como también el diálogo y la apropiación de distintas fuentes, se relacionaron con un tipo de escritura concebida como memoria colectiva de un patriotismo criollo pensado como laboratorio de experimentación política. Patriotismo articulado como discurso con procedimientos narrativos del Antiguo Régimen y contenidos propios de una cultura política moderna constitucional todavía en ciernes para el año de 1813.

\section{ConCLusión}

Mier instaura en el libro XIV una minuciosa refutación política-cultural que transformaría sobre la autonomía americana en una defensa con raigambres históricas. De hecho, utiliza este libro como el espacio propicio para "presentar el verdadero estado de la cuestión entre americanos y europeos" (1990, pp. 10-11). Para ello, consideró los relatos sobre el accionar heroico y conquistador de los españoles como fábulas ridículas desenmascaradas por las versiones de ciertos historiadores peninsulares (Acosta, Torquemada, Solórzano, Herrera): "a la América se debe todo el respeto y consideración en que ha permanecido y es dudoso que sin ella tuviese hoy [España] ni el rango de nación" (p. 602); "En una palabra, nada podéis sin nosotros; y en realidad vosotros sois los protegidos, no los protectores. ¡Protección sin dinero, sin armas, sin marina!" (p. 603).

Más que defender una revolución institucional ante otra insurgente y popular (Annino, 2008), el mérito de Mier residió en adaptar el discurso identitario-cultural del patriotismo criollo a los tiempos políticos y vertiginosos inaugurados a partir de 1808 y ampliar ese discurso a fin de abarcar a todos los sectores "desprotegidos" de las Américas. Dentro de la trama que propuso Mier, no nos es posible escindir la búsqueda de la autonomía política americana de la insurgencia o los debates constitucionales. Para lograr 
su objetivo, Mier planteó una particular articulación de la historia de la revolución que pivoteó sobre tres momentos fundacionales como fueron la lucha frustrada por la autonomía política novohispana en 1808 y sus continuidades tanto en la insurgencia criolla de Nueva España (1810-1815) como en los debates constitucionales de las Cortes de Cádiz (1810-1812).

\section{ReFERENCIAS}

Annino, A. (2008). 1808: el ocaso del patriotismo criollo en México. Historia y Politica, 19, 39-73.

Ávila, A. (2002). En nombre de la nación. La formación del gobierno representativo en México (1808-1821). México: Taurus-CIDE.

Brading, D. (1980). Fray Servando Teresa de Mier. En Los orígenes del nacionalismo mexicano (pp. 43-95). México: Ediciones Era.

Brading, D. (1998 [1991]). Orbe indiano. De la monarquía católica a la República criolla 1492-1867. México: Fondo De Cultura Económica.

Cañizares-Esguerra, J. (1998). Spanish America in Eighteenth-Century European Travel Compilations: A New "Art of Reading" And the Transition to Modernity. Journal of Modern History, 2(4), 329-349.

Cañizares-Esguerra, J. (2007). Cómo escribir la historia del Nuevo Mundo. Historiografías, epistemologias e identidades en el mundo del Atlántico del siglo XVIII. México: FCE.

Domínguez-Michael, C. (2005). Vida de Fray Servando. México D. F.: Ediciones Era.

Goren Bitrán, Y. (2011). Servando Teresa de Mier. En V. Guedea (coord.), El surgimiento de la historiografía nacional (pp. 65-92). En J. A. Ortega y Mediina y R. Camelo (coords.), Historiografía mexicana. México: Universidad Autónoma de México.

Hutcheon, L. (1992). Ironía, sátira y parodia. Una aproximación pragmática a la ironía. En H. Silva (ed.), De la ironía a lo grotesco (pp.173-193). México: Universidad Autónoma Metropolitana Iztapalapa.

Jáuregui, C. (2008). Canibalia. Canibalismo, calibanismo, antropofagia culturaly consumo en América Latina. MadridFrankfurt: Iberoamericana/Vervuert.

Lafuente Ferrari, E. (1941). El virrey Iturrigaray y los origenes de la Independencia de Méjico. Madrid: Consejo Superior de Investigaciones Científicas-Instituto González Fernández de Oviedo.

Lempérière, A. (2008). Los hombres de letras hispanoamericanos y el proceso de secularización (1800-1850). En C. Altamirano (ed.), Historia de los intelectuales en América Latina (pp.242-266). Buenos Aires: Katz Editores.

López Cancelada, J. (1811). La verdad sabida y buena fe guardada: origen de la espantosa revolución de Nueva España comenzada en 15 de setiembre de 1810. Defensa de su fidelidad. Cuaderno primero... México: Documentos publicados en la Gazeta de México.

Mier, S. T. de (1990). Historia de la revolución de la Nueva España antiguamente Anábuac o verdadero origen y causas de ella con la relación de sus progresos hasta el presente año de 1813. Edición, introducción y notas por Saint-Lu, André y Marie-Cécile Bénassy-Berling (coords.) y otros. París: Publications De La Sorbonne.

Mier, S. T. de (1982). Sermón guadalupano. En E. Villar de la Torre y R. Navarro de Anda (comps.), Testimonios históricos guadalupanos (pp.730-757). México: Fondo De Cultura Económica.

Moreno Gutiérrez, R. (2004). La idea de América al tiempo de la independencia. Nueva España, 1808-1821. Tesis inédita de Licenciatura en Historia. México: UNAM.

O'Gorman, E. (1981). Estudio preliminar. En S. T. de Mier., Obras completas. Tomo I-El heterodoxo guadalupano (pp. 23-130). México: Universidad Nacional Autónoma de México.

Paniagua, J. (2007). Edición, introducción, notas, glosario e índices. En P. B. Pino y J. López Cancelada. Exposición suscinta y sencilla de la Provincia del Nuevo México y otros escritos. León: Universidad de León.

Paniagua, J. (2008). Edición, introducción, notas e índices. En J. López Cancelada (ed.), El Telégrafo Americano (10 de octubre de 1811-31 de marzo de 1812). León: Universidad de León.

Padgen, A. (1991). El Imperialismo español y la imaginación política. Barcelona: Planeta. 
Pasino, A. (2010). Los escritos de Manuel J. Quintana y José M. Blanco White en el Semanario Patriótico (1808-1810); sus aportes a la construcción del lenguaje del primer liberalismo español. Anuario del Centro de Estudios Históricos "Prof. Carlos S.A. Segreti", 10, 343-363.

Portillo Valdés, J. M. (2006). Crisis atlántica. Autonomia e independencia en la crisis de la monarquía hispana. Madrid: Fundación Carolina/Centro de Estudios Hispánicos e Iberoamericanos/Marcial Pons- Ediciones de Historia.

Rodríguez, O. J. E. (1988). Introducción. En S. T. de Mier, Obras completas, Volumen IV-La formación de un republicano (pp. 7-30). México: Universidad Nacional Autónoma de México.

Torres Puga, G. (2013). La transformación de la Gazeta de México, 1805-1808. En M. A. Landavazzo y M. Guzmán Pérez (eds.), Guerra, politica y cultura en las independencias hispanoamericanas (21-58). Morelia: Universidad Michoacana de San Nicolás de Hidalgo-El Colegio de Jalisco.

Vega, G. de la (1976 [1609]). Comentarios reales. Caracas: Biblioteca Ayacucho.

White, H. (2003). El texto histórico como artefacto literario y otros escritos. Barcelona: Paidós.

Zárate Toscano, V. (1986). Juan López-Cancelada. Vida y obra. Tesis inédita de la maestría en Historia. México: Universidad Nacional Autónoma de México.

\section{Notas}

1 Al respecto, se sugieren los estudios de O'Gorman (1981); Rodríguez (1988); Brading (1980; 1998); Goren Bitrán (2010); Domínguez-Michael (2005); Portillo Valdés (2006) y Annino (2008).

2 Esta postura crítica concibió la escritura histórica de forma instrumental para un lector inglés como un puente para producir cambios en América. Esta lectura fue elaborada en la edición que coordinaron André Saint-Lu y Marie-Cécile Bénassy-Berling: "Mier quiere contestar a sus amigos americanos e ingleses, que le urgen para que continúe la Historia, porque desean un nuevo intento de mediación y le ofrecen documentos para restablecer la verdad" (p. XXV).

3 Para contextualizar los debates y pugnas institucionales de 1808 y el golpe de Gabriel de Yermo, destacamos las investigaciones de Lafuente Ferrarri (1941); Zárate Toscano (1986); Ávila (2002); Moreno Gutiérrez (2004); TorresPuga (2013) y Paniagua $(2007 ; 2008)$, entre otros.

4 Luego de su detención y destierro de la ciudad de Nueva España, donde ejercía la labor de editor de la Gazeta de México (1805-1809), el periodista y comerciante Juan López de Cancelada publica en la ciudad de Cádiz este escrito en el que desea probar la "defensa de la fidelidad" del virreinato de Nueva España frente a la cruenta revolución que se gestó desde el año de 1808. Este escrito fue financiado por el Consulado de México y por ciertos comerciantes peninsulares residentes en Nueva España. Es interesante observar cómo en esta obra Cancelada concibe la rebelión popular de Hidalgo como continuación de una revolución novohispana iniciada por ciertos funcionarios criollos y que contó con la venia del exvirrey Iturrigaray.

5 "Cuando la guerra explotó, las facciones rivales lograron convertir una disputa por los derechos de representación política en las Cortes de Cádiz (1810-1814) en una disputa historiográfica, en donde los temas de credibilidad y autoridad se volvieron primordiales" (Cañizares-Esguerra, 2007, p. 563).

6 Todas las referencias a la Historia de la revolución de Mier se extraerán de esta edición. Se modificó para este trabajo la grafía y ciertos usos gramaticales de la escritura de Mier para adaptarlas al uso gramatical actual.

7 Annick Lempérière aclara que los hombres de letras no tenían en el período independentista a su disposición la palabra "secularización", ya que esta pertenecía exoficio al vocabulario de las instituciones eclesiásticas. Sin embargo, plasmaron el concepto mediante el uso muy difuso de otros dos: "civilización" y "sociabilidad". Nos interesa la forma que tiene esta historiadora de plantear la secularización como el nuevo posicionamiento y conciencia del rol de los hombres de letras en el dominio y vehiculización de la palabra escrita e impresa (2008, p. 247).

8 Con respecto a la ironía, sostiene Linda Hutcheon: "[L]a ironía es esencial para el funcionamiento de la parodia y de la sátira, aunque de manera distinta. Dicho de otro modo, la ironía goza de una especificidad doble -semántica y pragmática(...). La ironía es, a la vez, estructura antifrástica y estrategia evaluativa, lo cual implica una actitud del autor- codificador con respecto al texto en sí mismo. Actitud que permite y exige, al lector-descodificador, interpretar y evaluar el texto que está leyendo" (1992, p.175, 177).

9 "Suplico al lector se contente con hallar la verdad según mi leal saber y entender, porque desde luego le confieso los defectos consiguientes no solo a la pequeñez de mi talento y a la falta necesaria de plan, sino a la de reposo y de tiempo para digerirla mejor o darle la lima correspondiente" (Mier, 1990, p. 11).

10 "Por tramado entiendo simplemente la codificación de los hechos o contenidos en las crónicas como componentes de tipos específicos de estructura de tramas" (White, 2003, p. 112). 
11 Contra lo que se difundió intencionadamente en la península, el mexicano y otros agentes contemporáneos, muestran que no era, como presumía la mente colonial, la separación del cuerpo hispano lo que perseguían aquellas juntas. Para ellas se trataba, por decirlo de modo más gráfico, de llegar a declaraciones de autonomía y no de independencia. Por ello el lenguaje apropiado era el legal y constitucional (Portillo Valdés, 2006, p. 81).

12 Según el Diccionario de Autoridades: INDIANO. Usado regularmente como substantivo, se toma por el sugeto que ha estado en las Indias, y después vuelve a España. Latín. Indus, i. BROCENS. Doctr. de Epict. cap. 1. Acuerdome que repliqué yo sobre esto a un Indiano rico, que tenía un hermano viejo mui pobre. LOP. Dorot. f. 5. Debe de ir ahora a que la premie por ventúra el Indiano.

$13 \mathrm{Al}$ respecto sostiene Cañizares-Esguerra: "Los criollos se vieron a sí mismos naturales de sus reinos locales y discriminaron a los peninsulares como extranjeros incapaces de amar y cuidar a las comunidades locales” (1998, p. 433) (Traducción mía).

14 Más allá de la lectura demoníaca que realizó Torquemada sobre las costumbres religiosas y sociales que movían a los aztecas en su vida cotidiana.

15 Cañizares-Esguerra entiende este concepto como "un discurso eclesiástico y aristócrata ligado a un conocimiento histórico en que las fuentes se juzgaban de acuerdo con una escala móvil de credibilidad, la cual, a su vez, estaba vinculada a jerarquías raciales y sociales (...). De acuerdo con esta peculiar perspectiva, los defectos historiográficos del pasado se atribuían al uso inadecuado que se hizo de buenas fuentes amerindias. Los epistemólogos patriotas argumentaron que las primeras historias se habían basado en el testimonio erróneo de plebeyos amerindios coloniales o en relatos confiables de los nobles amerindios precolombinos o de principios de la colonia pero que fueron malinterpretados. Distinguir entre el testimonio de informantes amerindios de clase alta y el de los plebeyos era fundamental para la nueva historiografía hispanoamericana" (2007, pp. 24-25).

16 "Todas, como se ve, son leyes remuneratorias anexas al pacto social de los americanos criollos con los Reyes, como que las consiguieron sus padres con pactos onerosos, y por consiguiente inalterables" (Mier, 1990, p. 488). Según el historiador Yael Goren Bitrán, "La Carta Magna a la que hace alusión Mier eran las Leyes de Indias. Sin embargo, desde la óptica de Mier, estas condiciones se habían roto pues la monarquía española había oprimido a todas las clases sociales en América" (2011, p.77).

17 Comentarios Reales, libro IX, cap. 31. 